\title{
ENZYMES OF RESPIRATORY IRON OXIDATION
}

\author{
PROGRES8 REPORT
}

March, 1990 - November, 1991

Grant NO. DE-FGO5-B5ER13339

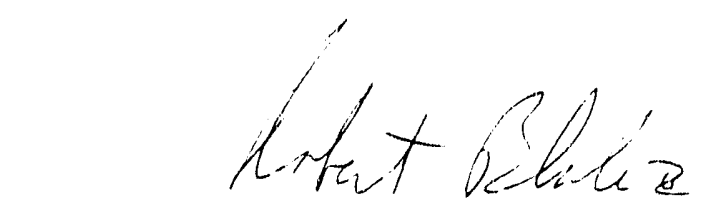
Robert Blake II, Principal Invastigator
Department of Biochemistry
Meharry Medical College
Nashvillia, Tennessee
37208

\section{DISCLAIMER}

This report was prepared as an account of work sponsored by an agency of the United States Government. Neither the United States Government nor any agency thereof, nor any of their employees, makes any warranty, express or implied, or assumes any legal liability or responsibility for the accuracy, completeness, or usefulness of any information, apparatus, product, or process disclosed, or represents that its use would not infringe privately owned rights. Reference herein to any specific commercial product, process, or service by trade name, trademark, manufacturer, or otherwise does not necessarily constitute or imply its endorsement, recommanufacturer, or otherwis by the United States Government or any agency thereof. The viesvs and opinions of authors expressed herein do not necessarily state or reflect those of the United States Government or any agency thereof. 


\section{A. CURRENT SPECIFIC AIMS}

The scope of work outlined in the current proposal contained three specific aims to be accomplished within three years. Accordingly, experimental progress to date ( 1.7 years) on each of these aims is summarized below.

specific Aim \#1 - To develop an improved procedure for the routine large scale culture of iron-oxidizing chemolithotrophs based on the in situ electrolysis of the soluble iron in the growth medium

The goal was to assemble an electrochemical apparatus whereby large quantities of autotrophic iron oxidizing chemolithotrophic bacteria could be achieved on a reproducible basis. The hypothesis to be tested was whether we could supply bacteria that respire on iron with an endless supply of growth substrate by electrochemically reducing the soluble iron in the media in situ. Such an electrochemical apparatus was successfully assembled and tested. Typical yields of Thiobacillus feryooxidans, Acidianus (formerly sulfolobus) brierleyi, Metallosphaera sedula (the latter 2 are tharmoacidophilic iron oxidizers that became available soon after the start of this grant), and sulfobacilius thermosulfidooxidans (a Gram positive moderate thermophile) increased from $40 \mathrm{mg}$ wet weight/liter to over $1.0 \mathrm{~g}$ wet weight/liter, while the corresponding yields of strain $M-1$. (a Gram negative straight rod that respires only on iron, not sulfur) and Leptospirillum ferrooxidans increased from 20 to $400 \mathrm{mg}$ wet weight/liter. Furthermore, the bacterial cells cotained by this electrolytic procedure appeared to be identical to cells grown by normal batchwise culture methods with regard to cytochrome content and kinetic properties of aerobic respiration on reduced iron. We have been able to achieve enhanced yields of both $\underline{A}$. brierleyi and $\underline{M}$. sedula on a 40-liter scale, while the other iron-oxidizers were cultured electrolytically on a 220-1iter scale; we thus have the means to routinely generate sufficient cell mass for subsequent enzyme purification and other experimental purposes.

A manuscript that describes this electrochemical apparatus and its performance was published in Biohydrometallurgy 189 , representing the proceedings of the international biohydrometallurgy meetings held in Jackson Hole, Wyoming in August, 1989 (copy enclosed).

It is our intention to prepare an additional manuscript on this electrochemical culture method for a peer-reviewed journal. We are in the process of conducting a study of the relationship between the maximum growth yield and current passed (expressed as mg dry weight of bacteria per coulomb) for each phylogenetically distinct iron oxidizer that shows an increased cell yield in the above apparatus. Differences in the individual values of maximum growth yields should reflect differences ir. the efficiency of energy conservation from the same substrate by different organisms, and thereby the probability of different substrate oxidation pathways, electron transport mechanisms, and modes of energy conservation. 
specific Aim \#2 - To perform iron oxidation kinetic studies on whole cells using the oxygen electrode

The goal of these experiments was to obtain kinetic characterizations of the $\mathrm{Fe}$ (II)-dependent reduction of molecular oxygen as catalyzed by viable cell suspensions of each of the mesophilic and moderately thermophilic iron-oxidizing organisms listed above. Analogous experiments on the extremely thermophilic ironoxidizers are performed under the auspices of the office of Naval Research. We have examined only two organisms in detail to date: $\underline{T}$. ferrooxidans and $\underline{L}$. ferrooxidans. The rate of oxygen reduction by both organisms was a hyperbolic function of the $F e$ (II) concentration. T. ferrooxidans exhibited a $\mathrm{Km}$ and Vmax of $2.3 \mathrm{mM}$ $\mathrm{Fe}(\mathrm{II})$ and $3.2 \mathrm{ml}$ of $\mathrm{O}_{2} / \mathrm{hr} / \mathrm{mg}$ of total cellular protein, respectively, for the iron-dependent reduction of oxygen at $30^{\circ} \mathrm{C}$. L. ferrooxidans exhibited values of $0.2 \mathrm{mM} \mathrm{Fe}$ (II) and $2.5 \mathrm{ml}$ of $\mathrm{O}_{2} / \mathrm{hr} / \mathrm{mg}$ total protein for $\mathrm{Km}$ and $\mathrm{Vmax}$, respectively, at $35^{\circ} \mathrm{C}$. In addition, the iron-dependent reduction of oxygen by $\underline{T}$. ferrooxidans was dependent on the identity of the principal anion present in solution, with only sulfate and selenate supporting facile rates of reduction. These kinetic experiments will be extended to other types of iron autotrophs during the current grant period.

The results of these steady state kinetic experiments on whole cells comprise the information base necessary for the functional comparisons between intact cells and isolated biomolecules, as outlined in specific Aim $\# 3$ of the current proposal.

specific Aim \#3 - To identify, separate, purify, and characterize the individual cellular components that compiise each iron respiratory electron transport chain

A. Respiratory chain of T. ferrooxidans

A.1. Structural studies on rusticyanin

Rusticyanin, a type I blue copper protein, is a prominant redox-active biomolecule synthesized by $\underline{T}$. ferrooxidans during autotrophic growth on soluble ferrous ions. The complete amino acid sequence of the purified rusticyanin from $T$. ferrooxidans ATCC 23270 (the type strain) was determined by amino-terminal microsequencing techniques. The results demonstrated a protein of 155 amino acids containing one cysteine and no arginine residues. A structural model of the rusticyanin was proposed where the protein is principally a B-barrel comprised of $\mathrm{six}$ strands. This model is consistent with the circular dichroism data and computational predictions of the secondary structure of rusticyanin. A novel feature of the model is the hypothesis that Asp 73 (as opposed to a His residue in other blue copper proteins) may serve as a fourth copper ligand.

A manuscript entitled "Amino Acid sequence of the Blue Copper protein Rusticyanin from Thiobacilius ferrooxidans" was recently published in Biochemistry (copy enclosed). 
Subsequent experiments have focused on the determination of the tertiery structure of the rusticyanin. Dr. Menachem Shoham of Case Western Reserve University, Cleveland, $\mathrm{OH}$, has succeeded in crystallizing purified rusticyanin. He has attained crystals of sufficient integrity to achieve an $x$-ray diffraction pattern at $2.8 \mathrm{~A}^{\circ}$ resolution. This laboratory has sent him additional purified protein in the hopes that he can now achieve rusticyanin crystals that yield $x$-ray diffraction patterns at even better resolution. In the meantime, we have also sent purified protein to Dr. Jane Dyson, Scripps Institute, La Jolla, CA. Dr. Dyson will attempt to determine the tertiery structure of rusticyanin in solution by proton-, ${ }^{15} \mathrm{~N}-$, and $13 \mathrm{C}-\mathrm{NMR}$ techniques. This laboratory will grow $T$. ferrooxidans autotrophically in the presence of the appropriate isotopes and purify the isotopicallylabeled rusticyanin. By one means or another, we will obtain the tertiery stxucture of purified rusticyanin.

\section{A.2. Functional studies on rusticyanin}

The one-electron transfer reactions between soluble iron and purified rusticyanin were studied by stopped flow spectrophotometry in acidic solutions containing each of 14 different anions. These experiment were conducted, in part, to generate a broad picture of the electron transer reactivity between soluble iron and rusticyanin under a variety of solution conditions. The results of these kinetic experiments indicated that the rusticyanin may possess at least two distinct electron transfer pathways for liganded iron. The first pathway was characterized by a protein-independent pattern of electron transfer reactivity. For liganded iron in this category, the anion-dependent reactivity pattern could be quantitatively described solely by the physicochemical properties of the individual iron-anion complexes. The second pathway, utilized by citratoiron(II) and oxalacetatoiron(II), produced second order rate constants for the liganded iron-dependent reduction of rusticyanin that were as much as 2 orders of magnitude greater than those anticipated on the basis of the physicochemical properties of the two complexes. The principal conclusion was that anjon-specific interactions between the rusticyanin and selected liganded iron species do occur.

A manuscript entitlea "Effect of Divers Anions on the Electron-liransfer Reaction between Iron and Rusticyanin from Thiobacillus ferrooxidang" was recently published in Bicchemistry (copy enclosed).

Whether these anion-specific interactions have any bearing on the physiological role of the rusticyanin in the iron respiratory electron transport chain of $T$. ferrooxidans remains under investigation in this laboratory.

\section{B. Respiratory chains of other iron autotrophs}

While performing a survey to quantify the rusticyanin content of other strains of iron autotrophs, we were surprised to 
discover that iron-oxidizing organisms phylogenetically distinct from $\underline{T}$. ferrooxidans appeared to contain no rusticyanin whatsoever. Instead, we determined that phylogenetically distinct groups of iron-oxidizing organisms, in turn, appeared to express biochemically distinct electron transport chains when grown chemolithotrophically on soluble ferrous ions. Each type of electron transport chain was characterized by its own distinctive acid-stable, redox-active biomolecule. Thus, cell-free extracts of $\mathrm{L}$. ferrooxidans were dominated by large quantities of an acidstable, soluble red cytochrome that was reduced directly by ferrous ions. Similarly, cell-free extracts of $\underline{s}$. thermosulfidooxidans were dominated by large quantities of an acid-stable, membrane-associated yellow chromophore that was reduced directly by ferrous ions. probably the most productive hypothesis for current and future work is that each new organism must be analyzed on the assumption that it will exhibit at least some unique features in the molecular details of its iron respiratory chain. In this way, the stages of the oxidative processes that are common, if such exist, can eventually be identified.

A manuscript that includes these preliminary results entitled "Enzymes of Aerobic Respiration on Iron" was submitted to FEMS Microbiological Reviews to be published as part of the proceedings of Biohydrometallurgy, 91 , an international conference held in Troia, portugal, in september of this year (copy enclosed).

\section{Additional Experiments}

Additional experiments not described in the current proposal were performed. A series of mixed ligand complexes of $\mathrm{Fe}$ (II) and $\mathrm{Fe}$ (III) with cyanide and 1,10-phenanthroline were synthesized and their electron transfer properties were investigated. By introducing different substituents on the aromatic diimine and varying the stoichiometry of the substituted phenanthroline in the final organoiron complex, a series of substitution-inert electron transfer reagents were constructed with reduction potentials from 500 to $900 \mathrm{mV}$. Kinetic and thermodynamic experiments were performed on the electron transfer reactions of each of these substitution-inert iron complexes with both sulfatoiron and rusticyanin from $T$. ferrooxidans. The utility of these reagents in both probing the electron transfer reactivity of the rusticyanin and in performing and mediating reduction potential measurements was illustrated. This family of substitution-inert electron transfer reagents could prove useful in characterizing the reactivity of each of the very high potential respiratory chain components that are beginning to emerge in this research.

A manuscript entitled "Mixed Ligand complexes of Iron with cyanide and Phenanthroline as New Probes of Metalloprotein Electron Transfer Reactivity: Analysis of Reactions Involving Rusticyanin from Thiobacillus ferrooxidans" is in press at tho Journal of Biological Chemistry. 
B. RENEWAL proposal

The experimental plan remains intact relative to the original proposal.

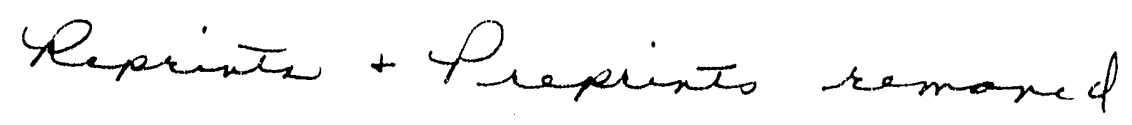

6 

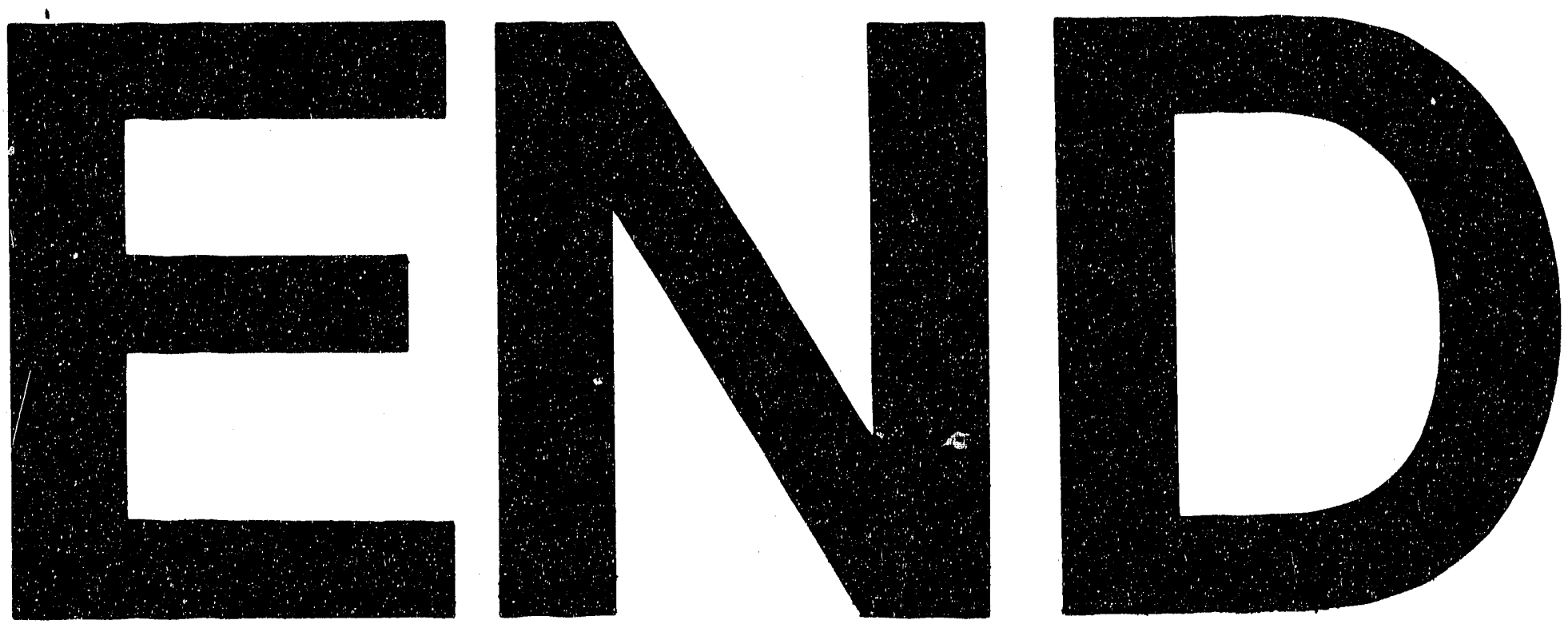

.
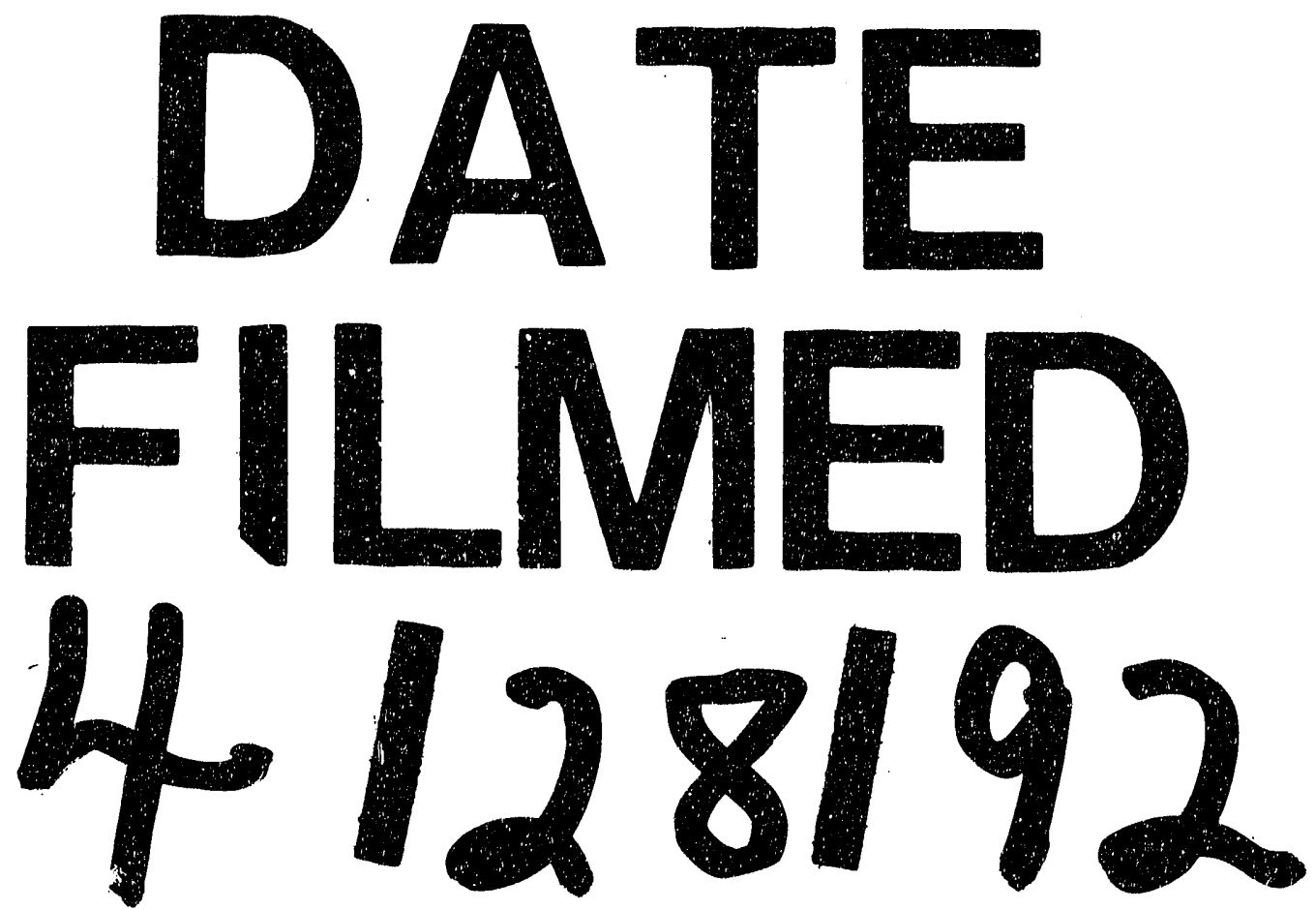
